\title{
INTELLIGENT BUMPER ACTUATION WITH BRAKING SYSTEM
}

\author{
A.Premkumar', T.Prem Kiran ${ }^{2}$, S.Prabhu Kumar ${ }^{3}$, A.Naveen ${ }^{4}$ \\ ${ }^{1}$ Department of Mechanical Engineering, RMK College of Engineering and Technology, Puduvoyal, Chennai \\ ${ }^{2}$ Department of Mechanical Engineering, RMK College of Engineering and Technology, Puduvoyal, Chennai \\ ${ }^{3}$ Department of Mechanical Engineering, RMK College of Engineering and Technology, Puduvoyal, Chennai \\ ${ }^{4}$ Department of Mechanical Engineering, RMK College of Engineering and Technology, Puduvoyal, Chennai
}

\begin{abstract}
In today's world vehicle accident is a major problem. To avoid this we have developed an automatic impact reducing system in our project. The system is based on intelligent electronically control system known as "Automatic pneumatic-bumper system". Automatic pneumatic bumper system uses infrared sensor (IR), which is used to sense the vehicle coming is front of our vehicle which is responsible for an accident. As soon as any object or vehicle is sensed by the sensor the sensor sends feedback signal to engine through the relay control to activate the Solenoid Valve which allows the flow of compressed air to the cylinder. During the working of Automatic Pneumatic Bumper system simultaneously the driver also try to stop the vehicle by applying brake pedal which somewhat slows down the engine. The compressed gas flowing through the solenoid valve will activate the cylinder which in turn activates the Bumper. This system provides pre-crash safety to the vehicle. As well as it improves the response time of vehicle braking to keep safe distance between the vehicles. By using this system we can obtain control over the speed of vehicle in short distance.
\end{abstract}

Keywords: Automatic Pneumatic Bumper System, IR Receiver, IR Transmitter, Electromechanical System, Solenoid Valve

\section{INTRODUCTION}

India is the developing country. India is a densely populated country with the vehicle usage being really diverse. While the available resources which are used to run the vehicles like road quality \& new technologies in vehicles are being developed to avoid accidents. The number of people expired during vehicle accidents is very large as compared to the other causes of death. Though there are different causes for accidents but proper technology of braking system and technology to reduce the damage during accident should be developed. Hence there is need of Impact Reduction system to prevent the accidents and to reduce the damage to vehicle and also the driver. To achieve this goal, we design this Automatic Pneumatic Bumper system. Our main aim is to design \& develop automatic control system based onintelligent electronic control automotive bumper activation system called "INTELLIGENT BUMPER ACTUATION WITH BRAKING SYSTEM'.

\section{OBJECTIVES}

The future of any industry is more than just developing new technology. It is integrating the approach towards achieving safety. Impact Reducing System approach represents considerable shift from the traditional approach to safety, by considering safety in terms of, Firstly avoiding the possibility of accidents, and secondly, protecting occupants when a crash is unavoidable, we can prevent more accidents, save more lives, decrease material damage to vehicles and reduce medicalcosts.
Following are the main objectives of Impact Reduction System with PneumaticBumpers:

- To ensure the braking of vehicle intime.

- To increase the crashing distance duringaccident.

- To increase the safety duringpre-crash.

- To increase external safety to vehiclebody.

- To decrease the level of passenger injury by use of external vehicle safetydevice.

- To reduce the requirement of internal safety deviceslike airbags.

\section{CURRENT TREND}

In conventional vehicles there are different mechanism operated for braking system like hydraulic, pneumatic, or mechanical system. But in all these braking mechanisms the input signal is to be given directly from the driver by applying the brake pedal. Thus, braking of vehicles is totally manual operated. So, if the driver fails to see the obstacle in front of his driving vehicle or fails to apply proper braking force on the brake pedal, he may lose the control of his vehicle, leading to accident. Also the driver may not able to pay complete attention when driving at night. So there are many chances of accidents. Urgent application of brakes may also result in imbalance by skidding of the tyres of the vehicle.

So, There are no arrangements to prevent or minimize the damage on the vehicle or the passengers. 


\section{CONSTRUCTION AND WORKING}

As this system is used at the time of emergency during work. In normal travelling of vehicle this system can be switched of with the help of a switch and it will not affect the normal working of the vehicle.

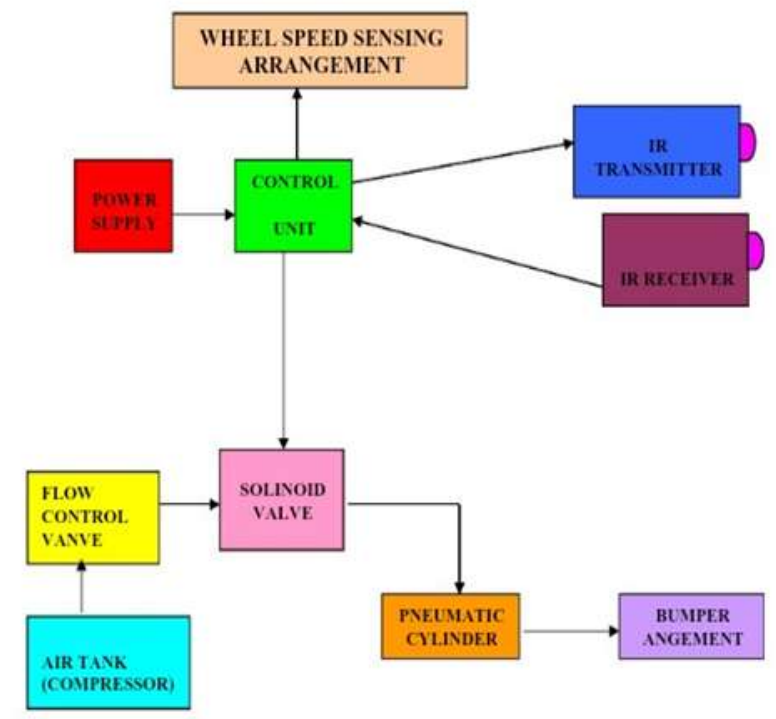

When any obstacle, human, animal or vehicle comes in front of the vehicle then the installed infrared sensor senses the obstacle. The range of distance between the vehicle and obstacle is variable. This range is varied according to the density of vehicles or humans on road. The received signal by IR sensor is provided to the control unit. When any obstacle, humans, animals or vehicle is came in front of the vehicle then the installed infrared sensor senses that obstacle. The range of distance between the vehicle and obstacle is variable. This range is varied according to the density of vehicles or humans on road. The received signal by IR sensor is provided to the control unit. The control unit then activates the Solenoid Valve which will allow the flow of compressed air through it. Compressed air is provided as an Input to the Solenoid Valve which has two Outputs both connected to the Double Acting PneumaticCylinder.

This pneumatic force of the compressed air through the Solenoid Valve is transferred to the Bumper System. The pneumatic force provides forward motion to the Bumper and it also retracts the bumper slowly reducing theimpact.

Hence, when the external body is kept safe, there will be no chance of internal damage.

\section{COMPONENTS AND DESCRIPTION}

\subsection{Double Acting Pneumatic Cylinder}

The cylinder is a Double acting cylinder, which means that the air pressure forward and backward operates on the strokes. The air from the compressor is passed through the solenoid valve which controls the pressure to the required amount by adjusting its knob.

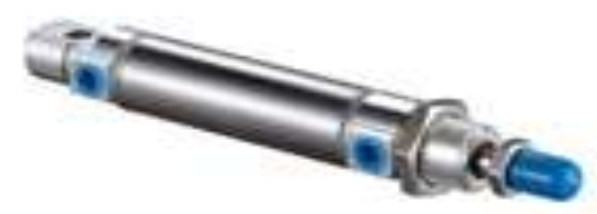

\subsection{Solenoid Valve}

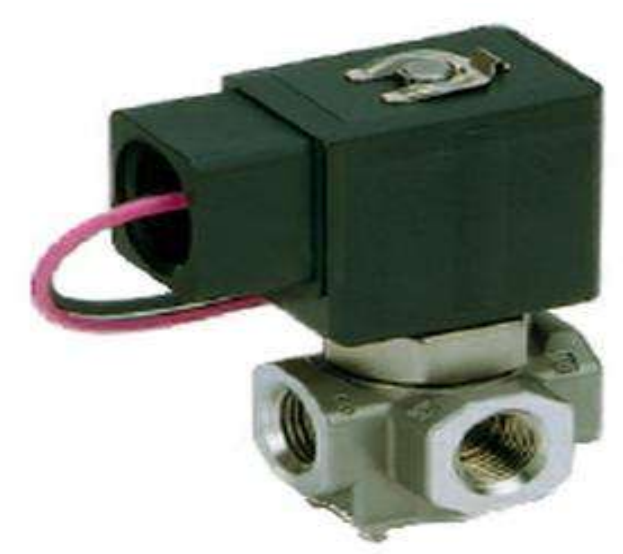

It is a flow control device used in pneumatic system to change the direction of air flow. Solenoid valve is used in automatic bumper system to control the compressed air towards the pneumatic cylinder during the extraction of the bumper. Different types of solenoid valves are available in market. But most common is $1 / 2$ solenoid valve and $2 / 5$ solenoid valve. $1 / 2$ means one way operation and two ports and $2 / 5$ means two way operation and five ports.

\subsection{AC Motor}

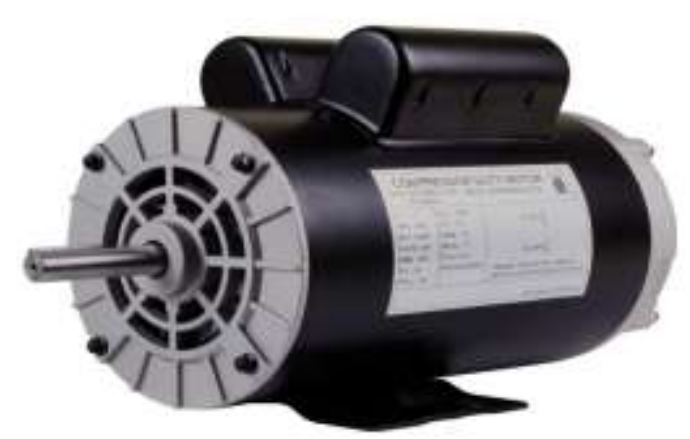


An electric motor is an electrical machine that converts electrical energy into mechanical energy. Electric motors are used to produce linear or rotary force (torque).

Gears will be attached to the motor which will help driving the chain drive which in turn will move our vehicle.

\subsection{IR Sensor Unit}

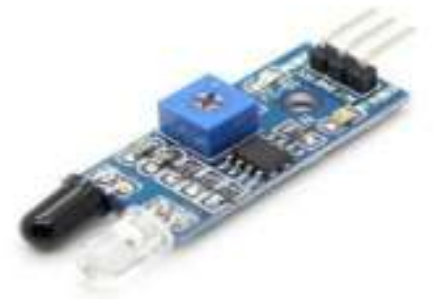

This unit consists of two components : IR Receiver and IR Transmitter. The IR transmitter transmits the signal from sensor. The IR Receiver after detecting any object sends signal to the control unit in order to activate the Solenoid Valve.

\subsection{Relay}

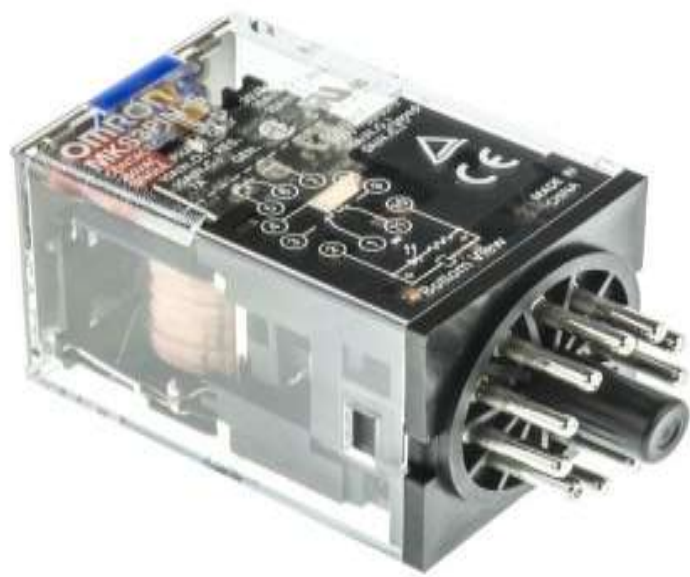

It is a control unit having certain specifications. This control unit acts according to the sensor signal to activate the Bumper with the help of compressed air through solenoid valve.

\section{FABRICATION}

\subsection{Frame with Axle and Wheels}

Initially frame is constructed in rectangular shape by welding angle bar. Then the four angle bars are welded to the main rectangular frame in order to mount all other components.
Pedestal bearings are mounted on both end of the axle to give support to the axle and reduce frictions for rotation. The wheels are mounted on both ends of the axle as shown in figure.

We have used Nylon Wheels here.

\subsection{Assembling All the Components}

All the components are assembled at their proper position. A proper mounting method is used to mount the components. Wiring can be done later.

\section{ADVANTAGES AND LIMITATIONS}

\subsection{Advantages}

1) Simple construction of the prototypevehicle.

2) It provides safety to passengers in the vehicle as wellas to the vehiclebody.

3) It reduces accident intensity andimpact.

4) This system increases the response time of vehicle braking by keeping safe distance between twovehicles.

5) The design also increases the crashing distance by providing extra space due to extension of thebumper, decreasing the chances of injuries tocommuters.

\subsection{Limitations}

1) IR sensor range issmall.

2) Proximity sensors may sense obstacle due topresence ofdirt.

3) Sensors may stop working due to randomreasons.

4) Not suitable for heavy vehicles

\section{CONCLUSION}

Behind the designing of this system, our main aim is to improve the technique of prevention of accidents and also reducing the hazard from accidents like damage of vehicle, injury of humans, etc.

This project work has provided us an excellent opportunity and experience, to use our limited knowledge. We have gained practical knowledge regarding, planning, purchasing, assembling and machining while doing this project work.

In conclusion remarks of our project work, we have developed an "INTELLIGENT BUMPER ACTUATION WITH BRAKING SYSTEM"which helps to achieve low Impact damage. We are proud that we have completed the work with the limited time successfully. We have done the project to our ability and skill making maximum use of available facilities and we are able to understand the difficulties in maintaining the quality. We have also observed that the prototype manufactured is working with satisfactory conditions and our work is able to achieve all the objectives which are necessary. 


\section{ACKNOWLEDGEMENT}

It indeed is a great pleasure and moment of immense satisfaction for us to have successfully completed the project of "Accident Prevention System by Automatic Pneumatic Bumper" and we take the opportunity to thank all those who provided us inspiring guidance and encouragement, we take the opportunity to thanks those who gave us their indebted assistance.

We wish to extend our cordial gratitude with profound thanks to our internal guide Asst.Prof. K.Rajeshfor his precise guidance.

\section{REFERENCES}

[1] G.B.S. Narang, “Automobile Engineering”, Khanna Publishers, Delhi, 1991, pp671.

[2] William H. Crowse, "AutomobileEngineering".

[3] Donald. L. Anglin, "AutomobileEngineering".

[4] Pneumatic Control System----Stroll \&Bernaud, Tata McGraw Hill Publications, 1999.

[5] Dr.EungSooKim,'Fabrication of Auto Braking System Using Sensor", International Journal Of control And Automation, Vol-2, andno1. 